\title{
The principal methods of reforestation in the Soviet Union
}

\author{
L. A. KAIRIUKSHTIS \\ Lithuanian Scientific Research Institute of Forestry \\ USSR State Committee of Forestry \\ Kaunas, Lithuania SSR
}

The manuscript was prepared for this publication by Erika E. Goertner and D. A. Fraser, Sir George Williams University, Montreal, P.Q.

There are 1,238 million hectares $(1$ ha $=2.47$ acres) of potential forest land in the Soviet Union, of which 738 million ha consist of forested lands. Thus a third of the total area of the USSR is covered by forest - an average of $3 \frac{1}{2}$ ha per person. Conifers make up $84 \%$ of the total volume, the principal genera being: larch $(37 \%)$, pine $(19 \%)$, spruce $(17 \%)$, cedar $(8 \%)$ and fir $3 \%)$. The total wood inventory exceeds 80 billion cubic meters, but its utilization in any region is far from complete because the annual volume of felling constitutes less than half of one percent of the total reserve.

In the Soviet Union, great emphasis is laid on reforestation. This indicates a concern not only for forest productivity, but also for field crop capacity and the esthetic effects which influence the life and work of its people. During the fifty years of Soviet power 18 million ha were converted into forests and 12 million ha were regenerated naturally. These 18 million ha compare with 900,000 ha for the period of the Tsarist regime between 1840 and 1917. During the last ten years there has been a steady increase in the area reforested, e.g. in 1955, 582,000 ha were directly seeded and planted, the area increasing to $1,279,200$ ha of the $2,171,300$ ha regenerated in 1967. An area of 21,500 ha was also planted under an anti-erosion and protection plan. This includes the planting of ravines and sandy areas.

A further increase in reforestation and other planting work in the Soviet Union is foreseen for the near future. According to the forest census of January 1,1966 , there were $9,447,900$ ha of land accessible to reforestation, which included 5,238,600 ha that required sowing and planting, and 4,209,300 that needed assistance with natural regeneration. The annual cut, which covers 2 to 3 million ha, must also be considered as some $30 \%$ of this land would not regenerate naturally.

While a large increase in reforestation is forecast for Siberia, the central regions, and the European north, a decrease will occur in the south and west regions, the Baltic republics, and the Caucasus because of an absence of uncultivated areas. Indeed areas of the Soviet Union on which reforestation is projected, except for the annual cut-over area, could be afforested within five years.
Reforestation methods for the whole country cannot be unified because natural, historical and economical conditions of the regions concerned differ. However, three distinct trends can be identified:

1 / Reforestation by natural regeneration aided by silviculture.

2) Artificial reforestation on cut-over areas, burned sites and under the canopy.

3 / Forest planting for field protection and antierosion.

Reforestation by natural regeneration aided by silviculture

This is of great importance in the densely wooded areas of the Soviet Union. It is based on the theoretical propositions of the classic Russian silviculturalist, G. F. Morosov, who defined wood cutting as a synonym of reforestation. Special laws concerning the final cutting are aimed at preservation of advanced growth. The techniques are designed to favour both natural regeneration under the canopy and in the cut-over areas.

Lately, several new schemes of logging and skidding on distinctly marked skid trails were introduced to preserve advanced growth. The total area of main and secondary roads, safety zones and loading areas, from which all trees are cut, must not exceed $15 \%$ of the cut-over area. The 'Kostroma way' has proved to be especially effective: trees are felled on top of trees that have been cut down first and then skidded out butt first. In this fashion 60 to $70 \%$ of the smaller advanced growth 0.5 to $1 \mathrm{~m}$ high is undamaged. Cutting of forest stands with fair to well established advanced growth is carried out in narrow strips, the trees are felled at an acute angle to the skid trails, and are skidded out by their tops the 'Udmurtian way' - permitting $50 \%$ of the important advanced growth to be saved. During the last five years, the introduction of these new techniques of mechanized logging has resulted in the preservation of more than 1.5 million ha of new growth in the Russian Federated Republic (comparable to a province in Canada).

In some of the zones of intensive forest utilization, different systems of shelterwood and selection cutting are designed not only to favour natural regeneration, but also to produce the maximum yield of wood per hectare from the mature forest, e.g. in 


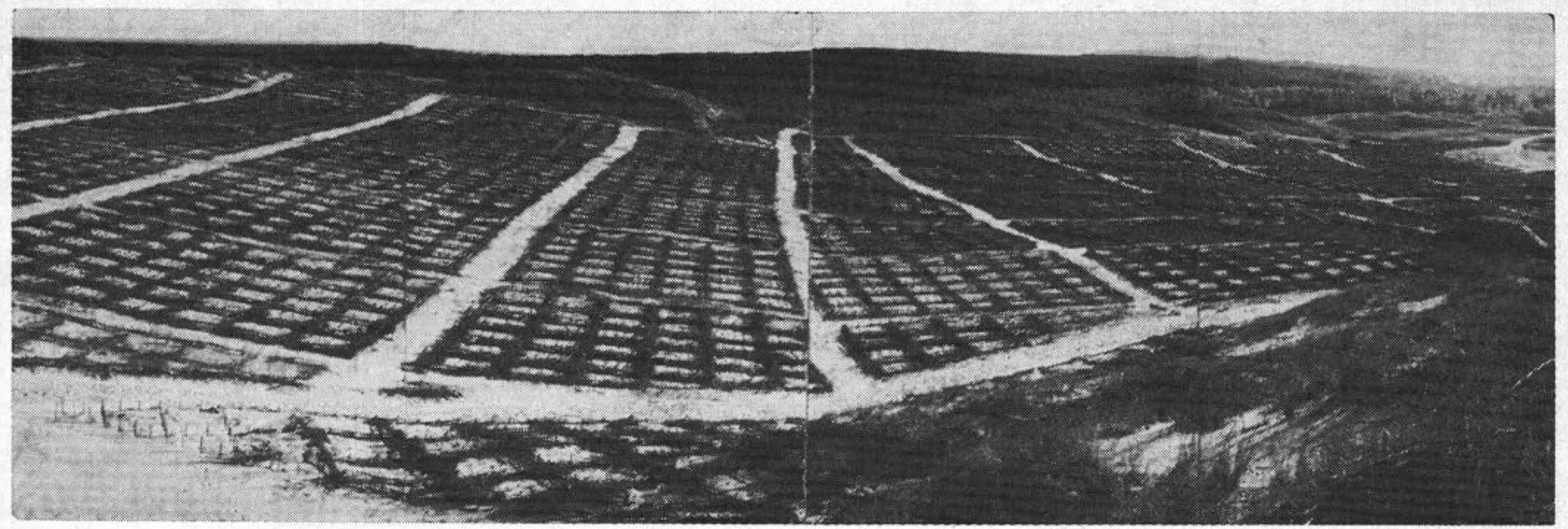

Pine (Pinus mugo) cultures on sand after mechanical fixation, Peninsula Kursiu Nerija, West Lithuania SSR.

Lithuania SSR, $80 \%$ of the final cutting of timber is obtained by such felling. Complete regeneration of the main species is obtained in spruce, spruce-oak, and spruce-hardwood stands by three successive stages of shelterwood cutting. In two-storied forest stands there is a two-cycle multistage cut carried out. Complex cutting schemes that provide equally for regeneration and qualitative improvement of a forest stand are also performed, for example the weak, suppressed and most vigorous trees are cut first.

Site preparation under the forest canopy is performed in Siberia and northern Europe by loosening the soil with cover strippers, rippers, cultivators and cutters when the sod is not well developed, and the moss-covered podzol soil is unfavourable to seed germination. More than 300,000 ha are thus treated annually. The methods are economically expedient when carried out during seed years or when combined with artificial sowing.

Seed trees are left standing in cut-over areas where either clear. cutting or very concentrated felling is practised. Seed trees are left in patches of 0.2 to 0.3 ha in spruce stands of every type. These patches constitute 5 to $10 \%$ of the cut-over area; in pine, larch and other forest stands, where the soil is not permanently wet, seed trees are left in small groups of 3 to 5 , with 5 to 10 groups per ha. Measures to assist natural regeneration are undertaken in cut-over areas. This is done in situ by clearing the logging slash to release the remaining undergrowth. Damaged trees are also removed. In winter, slash is burned as the trees are cut. In summer, when cutting on wet or sandy terrain, slash is used to strengthen skid trails. In areas situated between skid trails, tree tops and other sizeable slash are delimbed, chipped and firmly pressed into the soil. Slash is burned in piles 0.5 to $0.7 \mathrm{~m}$ high in cut-over areas on sandy and loamy soils. Sprouts on the burned areas are usually 3 to 4 times more numerous and grow better than elsewhere.

In commercial forests the accumulated slash accounts for from 300 to $1,600 \mathrm{~m}^{3}$ per hectare of cutting area. Since this slash hinders the 'reproduction' and disrupts silivicultural work, about 2 million ha have to be cleared every year with special gathering machines. Partial soil preparation in plots, strips and planting holes is performed mechanically on cut- over areas where aid to natural regeneration is necessary. These procedures ensure that an area of 700,000 ha annually will regenerate naturally from the seed.

Artificial reforestation on cut-over areas, burned sites, and under the canopy

This is the principal and most efficient means of reforestation of economically valuable species. The present tendency in reforestation is to increase areas of forest planting and decrease the amount of sowing and assistance to natural regeneration, because the latter are considered far less effective. Thus during 1968 , forest planting constituted $63 \%$ of the total area of reforestation. In some republics, e.g. Lithuania SSR, planting completely replaced sowing. Plantations make better use of their environment, grow faster in early stages, and mature earlier than natural stands. Sowing and assisting natural regeneration will not be completely abandoned because the majority of ruined forest stands, burned sites and waste lands are in remote, inaccesible districts where economic conditions prevent artificial reforestation.

Although more than a hundred species of trees and shrubs are grown in the USSR, the most important is Scots pine (Pinus sylvestris L.). The popularity of pine depends not only on its high value and widespread industrial application, but also on its high productivity and adaptability to a variety of soil types and climatic conditions. Spruce (Picea abies Karst) occupies second place, then comes English oak (Quercus robur L.), and various larches (Larix siberica Ledeb. $x$ L sukachewi Dyil. etc.) occupy an important place in the plantations. Within the last ten years poplars and other fast growing species have attracted much attention in the southern regions of the country.

The vast area of our country, with its diverse soil and climatic conditions, precludes a unified definition of the numerous silvicultural and agricultural methods. Planting techniques vary according to zones (forest, forest-steppe and desert) and regions (European, West Siberian, Far Eastern, Middle Asiatic and Mountainous). Different schemes (All Union Scientific Research Institute of Forestry and Mechanization (AUSRIFM), Leningrad SRIF and 
others) are developed in these zones for each group of forest types.

Silvicultural methods of reforestation usually consist of clearing the cut-over area and soil cultivation - including land improvement, the development of forest plantations and their maintenance. Clearing cut-over areas consists of gathering and chipping timber and slash. Plots intended for reforestation and over grown with shrubs and worthless tree crops are cleared by chemical brush killers. In cutover areas, where there are more than 600 stumps per hectare, a partial stump removal $\left(2 \frac{1}{2} \mathrm{~m}\right.$ wide strips set at $527 \mathrm{~m}$ intervals) is practised. Stump grubbers and a combination of herbicides and uprooting machines are used. In excessively wet places, stump removal is also effected with explosives.

Soil preparation. Soil cultivation depends on local conditions and the character of the overall formation and composition of the stand. Complete soil cultivation is performed in areas free of stumps. Partial soil cultivation is used widely on uneroded plains, fresh burns and old grassy cut-over areas where pines and oaks are usually planted.

The ground cover is partly removed and the soil cultivated on dry and sandy sites, so that the mineral soil is exposed in strips 5 to $10 \mathrm{~cm}$ deep at intervals of 0.5 to $0.7 \mathrm{~m}$ by various rippers and scarifiers. In Byelorussia and the Baltic Republics, both complete and partial cultivation of heathlands is done with disc harrows after preliminary stump removal.

In areas with fresh and moist sand and loam, strip furrows are ploughed with two-share ploughs or special tillers at intervals of 3 to $4 \mathrm{~m}$.

In excessively wet or temporarily water-logged cut-over areas, micro-elevations are formed by destruction of the herbaceous vegetation and by creation of drainage furrows. A favourable habitat is thus created for root establishment and subsequent tree development. A single-share plough and a forest-strip plough are usually used, which are suitable for the cluttered cut-over area. In the Baltic Republics, various mounted devices are used to build mounds of different height for hand planting of seedlings in groups.

By making drainage furrows the level of the water is lowered in the permanently water-logged cutover areas. The furrows are made by trench ploughs on previously cleared strips (at intervals of $5 \mathrm{~m}$, 0.4 to $0.8 \mathrm{~m}$ deep) simultaneously raising the soil on the sides of the furrows (60 to $97 \mathrm{~cm}$ wide and 35 to $40 \mathrm{~cm}$ thick). These raised parts are pressed down by a crawler tractor.

The mechanization of soil preparation in cut-over drained areas where peat is present is extremely difficult. The same machines are used as in the water-logged soils. A special tree planting combine coupled with application of mineral fertilizers is used in Latvia SSR.

Soil preparation in mountainous and hilly regions varies with the steepness of the slope. On slopes up to $8^{\circ}$, an overall soil preparation is used, forming at the same time water collecting furrows along the contours at intervals of 8 to $12 \mathrm{~m}$. These furrows prevent runoff and soil erosion. On 8 to $13^{\circ}$ slopes, the soil is prepared in contours $2 \frac{1}{2}$ to $5 \mathrm{~m}$ wide. On the 13 to $40^{\circ}$ slopes, terracing is applied. The terraces, on the average $3 \frac{1}{2} \mathrm{~m}$ wide, are formed with a reverse slope of $5^{\circ}$ using a terracer. Terracing is done by hand on slopes inaccessible by tractor.

Soil preparation techniques are continually being improved. For example, good results have been achieved recently with a special disc plough. It prepares the soil in $1.2 \mathrm{~m}$ strips that are enriched in humus and fertilizers, while on the temporarily water-logged soils ridge-like micro-elevations are formed.

In some regions of the country soil preparation is combined with liming of acid soil and culture of lupins. In the steppe and forest-steppe regions of the Russian Federation, gypsum is added to saline soils. Water-logged and marshy areas are drained. A total of 550,000 ha was drained between 1961 and 1965. Automatic machines are used more and more because they reduce labour costs considerably.

Establishment of plantations. Methods for establishment of planned forest plantations are determined by the conditions of the soil, their location, ecological characteristics of the tree species used and other factors.

Sowing of pine and spruce seed is widespread over the heavily cut-over areas of the forest zone. Sowing has proved to be both biologically and economically effective in fresh, sandy soils, but ineffective in areas overgrown by herbaceous vegetation; results were especially good on cut-over heath where moisture was sufficient. Seedling survival is better when seeds are sown in large patches, although according to N. N. Kalinichenko the method of sowing does not affect the growth of the seedlings. Sowing of conifers is also preferred in stony and gravelly soil where planting is difficult. In foreststeppe, the sowing of acorns is also widespread. Sowing is limited to the richer soils because of the spread of various grasses and root suckers. In temporarily water-logged and excessively wet soils the seedlings are heaved by late spring frosts.

Sowing is usually done simultaneously with soil preparation either by sowing in lines, in lines and holes, or in patches. It is done either by a sowing machine mounted on a stripper, ripper, or attached to a plough. Aerial seeding of pine and spruce is usually done in the north in late winter over the melting snow and this is also done in mountainous districts. Seed of saksaul (Haloxylon aphyllum Ilijn) is used in Middle Asia. Seeds of trees and shrub species collected locally are used for seeding. Seed from other districts is used only when it conforms with the district scheme of seed distribution, the reason being that seed from local sources and from comparable sites grows best. The suitability of seed is checked at special stations.

Planting represents the main method of cut-over 
area reforestation in the USSR. It is done both with and without previous soil preparation. In cut-over areas, where the soil is dry and sandy and the vegetation cover is scarce, pine seedlings are planted by machine without previous site preparation. Where the soils of the cut-over area are fresh, soil preparation may or may not be used. More attention is required when planting into the unprepared soil, because planting success depends entirely on the subsequent tending. Herbicides are also used in the course of planting and subsequent tending. When soil preparation and planting of seedlings is carried out together, planters are used with the plough. This method practically halves labour costs and slows down overgrowing of the layers and furrows by vegetation during the first year.

Planting in water-logged soil, where seedlings should be placed on micro-elevations, is especially difficult. A special machine is used for planting conifers on layers prepared by the plough. The results of such plantings depend on the stability of the slices, their coalescence with the soil substrate and provision of capillary moisture. The stability of layers is greater in the cut-over area where there are only a few stumps. The tree planter operates in strips free of stumps, when the soil is prepared and micro-elevations formed at the same time (12 to 15 $\mathrm{cm}$ high). Plantations established in this way root $25 \%$ better than when they are planted with the usual tree planter. In addition, mulching of these micro-elevations with the podzolic layer (horizon $A_{2}$ ) seems to control grass growth during the first three to four years. When the areas are waterlogged, planting is usually done by hand. A technique was recently developed at the Leningrad Scientific Research Institute of Forestry for mechanization of planting work with concomitant drainage of such soils. A two-row tree planter was designed to plant simultaneously on the two sloping sides of a deep furrow cut for improved drainage. Tree planters are equipped with automatic feed of seedlings to the planting slit, This increases the speed of planting two to three times.

Depending on the region, the standard 1- or 2year-old seedlings of pine and larch and 2- or 3year-old seedlings of spruce are usually planted, but the cost of preparation and subsequent cultivation of soil is probably reduced when oak and spruce saplings are planted. The planting of saplings 30 to $40 \mathrm{~cm}$ high is widespread in the Baltic Republics because it simplifies the cultivation of water-logged and weed-infested cut-over areas. The cost of these saplings is compensated through the smaller amount of work required for tending the following period of growth. Regardless of the technique used it is impossible to grow oaks either from seed or by planting in the Lithuania SSR because of the extremely large roe deer and hare populations.

Lately there has been a tendency to expand underplanting. In productive types of deciduous and mixed forest, 2,000 to 4,000 four- to six-year-old spruce are underplanted during the three to ten years before the final cutting. This is usually com- bined with a preliminary thinning of the original stand ( by successive culling) and the removal of shrubby vegetation. Strip preparation of the soil is also practised; it reduces root competition from the original stand. Compared with the usual planting procedures, underplanting decreases labour costs two to three times and prevents weed infestation from eradicating the planted species. It increases the forest productivity by 5 to $12 \%$. Underplanting as well as the introduction of soil improving species such as Tilia cordata, Alnus incana, Hippophea rhamnoides, etc. without the soil preparation has proven its value in Lithuania. The artificial introduction and cultivation of tolerant species in all lightdemanding stands is of industrial importance. Establishment of a forest with more than one canopy layer is being developed for the maximum utilization of solar energy, augmenting total stand production by 20 to $30 \%$. Thus introduction of the secondary canopy even in pine stands not only ensures a better growth and preservation of the primary stand, but also produces an additional $100-150 \mathrm{~m}^{3}$ / ha of timber until the final felling.

Type and upkeep of plantations. Types of forest plantations in the USSR are differentiated according to the forest zones, soil types and predominant species. A mixed forest is created in the steppe and forest-steppe zones in the Caucasus and the western region by planting of oak, larch, spruce and pine. Here, a fairly open upper canopy is formed by the light demanding species while a dense secondary story is formed by the tolerant species. The species are, as a rule, mixed in patches, strips and rows, according to their ecological requirements. Yet in all the main wooded regions pure stands of pine and spruce are usually developed. Here we take into account the bitter experience of the west European countries where the creation of monocultures brought about a decline in productivity and stability of forest stands. In northern forests an admixture of deciduous trees appears to be the natural way. The possible degradation of soils by conifers is counteracted by the natural alternation with deciduous forests of inferior quality. Mixed forest stands, where separate species are not strictly divided into separate stories, differ sometimes from pure stands of the same species by lower productivity.

It has been stated by Drs. Kondratjev, V. Rubtsov and $\mathrm{V}$. Timefejov that, although the average diameter of trees is smaller in very densely planted stands, the total productivity is higher over a short rotation. Yet over long rotations the total productivity of such plantations does not exceed that of normal density. In extremely dense plantation, trees overshadow each other and this is harmful to forest productivity. The number of seedlings per hectare and species planted are:

In the steppe zone with overall soil preparation 12,000 pine seedlings or 12,000 plots seeded with oak. In the forest-steppe zone with overall soil preparation -8 to 12,000 pine and spruce seedlings to 10,000 plots seeded with oak; with par- 
tial soil preparation, 5 to 7,000 oak and 6 to 8,000 pine and spruce seedlings. In the forest zone with partial soil preparation -4 to 5,000 spruce and pine seedlings and 2 to 2,500 larch seedlings.

When seedlings are grown under poor conditions due either to the lack of nutrients in the medium or severe competition with grass cover, primary density of planting is increased or seedlings are planted in dense groups. This helps to reduce the expenditure for replanting and upkeep.

Tending of forest plantations determines to a great extent the success of their establishment. This requires up to fifteen treatments during the first three to five years, according to the forest zone, type of soil and mode of preparation. Various cultivators and rippers are used. The cultivation of seedlings in rows or patches is performed mostly by hand. Soil sterilants are applied in combination with those of systemic action. When the canopy closes or becomes overgrown with foliage sprouts, thinning of a selective nature is performed. This type of work is not as yet sufficiently mechanized and is frequently done by hand, but special machines and mechanisms are coming into wider use.

\section{Heavy shelter-belt plantations}

Protection of fields and anti-erosion forest shelterbelt planting has an age-old history in the USSR. Theoretical principles for the planting of such forests have been worked out. They include the science of shelter-belt development, the effective distance and character of the protective influence, principles concerned with planting of the shelter-belts with regard to their prime use, and the main methods of growing such forests. The establishment of open wind breaks has proved to be most effective as it allows the width of the forest shelter-belts to be halved. Depending on the environment, the wind breaks are integrated with crop rotation and are made at a spacing of 7 to $15 \mathrm{~m}$ and at intervals of 300 to 600 $\mathrm{m}$. The shelter-belts, 12 to $21 \mathrm{~m}$ wide, are established only when the surface runoff is to be decreased. The spacing between rows in the shelterbelts of the forest-steppe zone is usually 2.5 to $3 \mathrm{~m}$, while in the steppe zone it is 3 to $5 \mathrm{~m}$. With a distance of 0.8 to $1.5 \mathrm{~m}$ between trees within a row, annual planting to protect fields amounts to 65,000 ha. Planting and tending of these plantations is completely mechanized.

Sand fixation and afforestation is performed annually on 84,000 ha. On shifting sands, preliminary mechanical fixation is performed together with mechanical loosening of the soil (without turning) through slits which are $40 \mathrm{~cm}$ deep and are formed in line. Strips of natural grass cover are left undisturbed. In the southern Ukraine, saplings 1.2 to 2 $\mathrm{m}$ high are planted. Mountain pine (Pinus mugo Turra) is planted along the shores of the Baltic Sea. Plots free of grass cover are afforested in the eroded sandy plains. Tree seedlings are planted in strips on sand overgrown with wormwood and grasses.

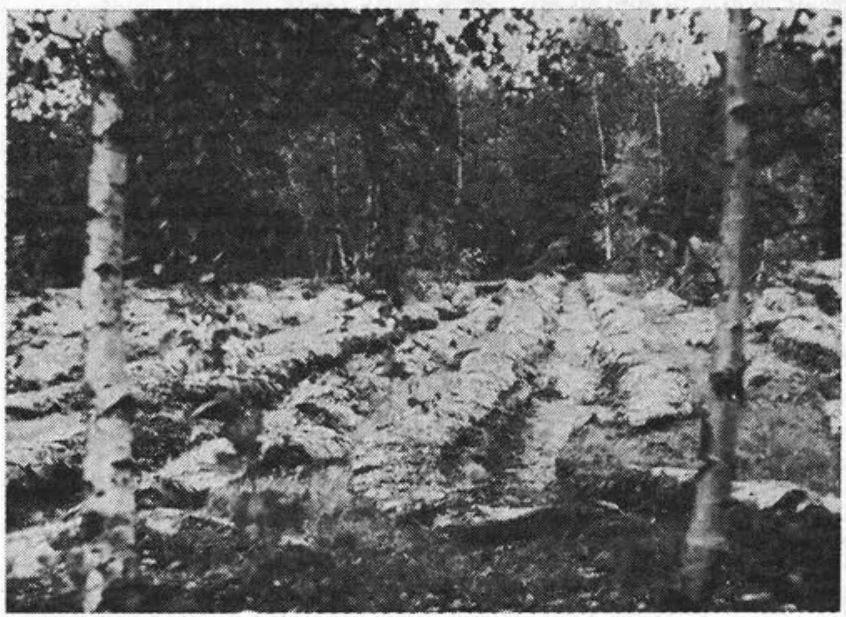

Preparation of moist soil with drainage furrows, Forest Ariogala, Lithuania SSR.

Planting of pine in fallow has recently been used successfully in the turf-steppe and sandy soils. This method decreases labour cost by $20 \%$ when compared with the usual planting on beach sand. Fixation of shifting sands without the construction of mechanical covers is economically sound. The roots of large species, such as poplar and acacia, are buried 30 to $40 \mathrm{~cm}$ below the sand surface. This reduces planting costs two to three times compared with the method of using longitudinal mechanical covers made from reed. The area planted each year to prevent erosion amounts to 150,000 ha. The creation of orchards and plantations around industrial centres in woodless regions is becoming popular.

\section{Future developments}

Further development of reforestation in the USSR can be characterized by better knowledge and use of the biological laws of natural regeneration and the technical potential of afforestation. The selection of forest species for afforestation and the prospective structure of the growing tree crop are more and more based on the topological study of the forest, development of forest soil maps and the design of maps of the future forests. The selection estimation (bonitas) of mature and advanced stands has performed, at present, the selection of closed wood seeding, the selection of plus trees and of forest stands. Development of seed plantations and the organisation of special seed farms will soon allow afforestation by the sowing of elite trees and seeds with improved hereditary qualities.

All these complex methods of reforestation and the creation of new, highly productive forest plantations for various purposes are carried out according to the state plan. Ideas on reforestation and forest planting can be found in the works of several generations of scientists. At present more than twenty scientific forest research institutes and chairs of higher learning are developing all these new ideas. 